\title{
Effects of Alpha Lipoic Acid on Motor Function and Antioxidant Enzyme Activity of Nerve Tissue After Sciatic Nerve Crush Injury in Rats
}

\author{
Sarper KOCAOGLU1', Ozgur AKTAS², Oguzhan ZENGI, Azmi TUFAN², Feyza KARAGOZ GUZEY² \\ ${ }^{1}$ Kirklareli State Hospital, Neurosurgery Clinic, Kirklareli, Turkey \\ ${ }^{2}$ Health Sciences University, Bagcilar Training and Research Hospital, Neurosurgery Clinic, Istanbul, Turkey \\ ${ }^{3}$ Health Sciences University, Bagcilar Training and Research Hospital, Biochemistry Clinic, Istanbul, Turkey \\ This study has been presented at the Symposium of Spinal Deformities between 29 October - 01 November 2015 at Antalya, Turkey and has been \\ selected as the report of the year.
}

\section{ABSTRACT}

AIM: To evaluate the protective, and if found to be effective, the therapeutic effects of Alpha lipoic acid (ALA) on functional and biochemical parameters in an experimental model of crush peripheral nerve injury in rats.

MATERIAL and METHODS: Twenty-eight Sprague-Dawley rats were divided into four groups: In Group 1 (sham group), the sciatic nerve was explored but another procedure was not performed. Sciatic nerve crush injury was performed with aneurysmal clip application after physiological saline injection intraperitoneally in Group 2 (control group), and samely, sciatic nerve crush injury was performed with aneurysmal clip application following ALA injection in Groups 3 and 4. In all subjects, the Sciatic Functional Index (SFI) was calculated with Walking Track Analysis before and after nerve injury. All subjects were sacrificed 1 hour after sciatic nerve injury in the first three groups, and 48 hours later in Group 4, and then sciatic nerve tissue samples were taken. Superoxide dismutase, catalase and glutathione peroxidase activities were evaluated in these samples.

RESULTS: Values of SFI of Group 1 were significantly higher than the results of Groups 2 and 3 ( $p=0.001$ and $p=0.004$, respectively). Results of SFI of Group 2 were significantly lower than the results of Groups 3 and 4 ( $p=0.002$ and $p=0.003$, respectively), and also, results of SFI of Group 3 were significantly lower the results of Group 4 ( $p=0.018$ ). However, values of SFI in the sham group were not significantly different than the values of Group 4. Administration of ALA before nerve injury provided significantly higher levels of three antioxidant enzymes in sciatic nerve tissue compared to the levels of the control group. In addition, antioxidant enzyme levels were significantly higher 48 hours after injury than levels measured 1 hour after injury ( $p=0.002$ for all three enzymes).

CONCLUSION: ALA that was given before crush type peripheral nerve injury was used for decreasing damage of the nerve and showed a distinct protective effect. Besides, this effect was more prominent 2 days after injury than the early period. However, specific mechanisms of this effect must be clarified and it must be made clear whether ALA is effective in other types of peripheral nerve injuries and also whether it is effective when given after injury.

KEYWORDS: Alpha lipoic acid, Antioxidant, Crush injury, Experiment, Oxidative stress, Peripheral nerve injury, Rats 


\section{INTRODUCTION}

A Ithough peripheral nerve injuries are not usually lifethreatening conditions, they cause frequently serious disabilities affecting daily practices of patients and an important socioeconomical burden because of their frequency. There are various peripheral nerve injury types. Most common ones are stretch-related injuries, lacerations by sharp objects, compression traumas and crush injuries. The crush type is especially common in high-energy traumas such as traffic accidents, falls from height or gunshot wounds (9).

Functional recovery after peripheral nerve injury is not often well; however, unlike in the central nervous system, regeneration in the peripheral nerves is possible (7). After peripheral nerve injury, ischemic and inflammatory processes begin and cause neurological impairment as in central nervous system trauma. Various drugs, metabolites and chemical substances or some energy types such as low level laser irradiation or low-frequency magnetic fields were tried to lessen these secondary insults of peripheral nerve injury, and many studies are still ongoing (45).

Alpha lipoic acid (ALA), also called thioctic acid, is a powerful antioxidant as well as a chelator for metals that is contained naturally in the body. One of the most important features of this small molecule is that it is both water-soluble and lipidsoluble and it can therefore easily distribute into the whole body including the nervous system (24). It was found useful in experimental models of various peripheral and central nervous system diseases such as diabetic neuropathy, multiple sclerosis and autoimmune encephalomyelitis, cerebral ischemia-reperfusion, excitotoxic amino acid brain injury, and spinal cord ischemia, in addition to cardiovascular diseases such as ischemia-reperfusion injury (10). It is also used for treating pain disorders such as diabetic neuropathy, sciatica and carpal tunnel syndrome in clinical practice $(7,27)$.

We planned a series of experimental studies to evaluate the protective, and if found to be effective, the therapeutic effects of ALA on functional and biochemical parameters in an experimental model of crush peripheral nerve injury in rats.

\section{MATERIAL and METHODS}

This experimental study was approved by the Bagcilar Training and Research Hospital Local Ethics Committee (decision 2013/36 dated $7^{\text {th }}$ October 2013) and financially supported by the Bagcilar Training and Research Hospital Administration. Animals were provided from the Bagcilar Experimental Research and Skill Improving Center (BADADEM), and the study was performed at the same center.

A total of 28 Sprague-Dawley female adult rats weighing 250350 grams were used. They were fed by standard rat diet with free access to their food and water during the study period excepting 2 hours prior to the operation. One hour before the operation, Walking Track Analysis (WTA) was performed in all subjects to calculate the Sciatic Functional Index (SFI) as previously described $(3,21,43)$. Rats were anesthetized with $7 \mathrm{mg} / \mathrm{kg}$ xylazine and $80 \mathrm{mg} / \mathrm{kg}$ ketamine intramuscularly.
The left sciatic nerve was explored in the gluteal region under the operating microscope in a standard manner. After exposure of the nerve, it was crushed with a standard straight titanium aneurysm clip with $135 \mathrm{gr}$ closing pressure for 60 seconds. After a 60 second waiting period for revascularization, the incision was closed and the subjects woke up.

The rats were randomly divided into 4 groups:

1- Group 1 (sham operated group): The sciatic nerve was explored without any injection before the operation and the nerve was not crushed.

2- Group 2 (control group): Starting 1 hour before the operation, physiological saline (PS) $100 \mathrm{mg} / \mathrm{kg}$ was administered intraperitoneally for 24 hours. After that, the sciatic nerve was explored and also crushed with a titanium aneurysm clip.

3- Group 3 (1 hour study group): Starting 1 hour from the operation, ALA $100 \mathrm{mg} / \mathrm{kg}$ was administered intraperitoneally for 24 hours and the nerve was explored and crushed.

In these three groups, WTA was repeated 1 hour after the operation. After the rats were sacrificed with high dose anesthetic agents, one $\mathrm{cm}$ long sciatic nerve samples centered on the crushed site were obtained.

4- Group 4 (48 hours study group): Before 1 hour from operation, ALA $100 \mathrm{mg} / \mathrm{kg}$ was administered intraperitoneally for 24 hours and the nerve was explored and crushed. Rats were allowed to live in routine cage conditions without any food or water restriction for 48 hours. WTA was repeated 48 hours after the operation. Nerve samples were taken following the sacrificing of the subjects.

Superoxide dismutase (SOD), catalase (CAT) and glutathione peroxidase $(\mathrm{GSH})$ activities were measured in the nerve samples in all groups.

\section{Walking Track Analysis and Sciatic Functional Index}

A walking track, $8.2 \mathrm{~cm}$ width and $42 \mathrm{~cm}$ long with $12 \mathrm{~cm}$ height walls, and ending in a dark chamber was used, and SFI was calculated as described before $(3,21,43)$. White paper was located on the track. Posterior paws of the subjects were pressed down onto a stamp pad soaked with black ink and rats were allowed to walk along the walking track. Therefore, their footprints were captured on the paper. Three parameters were measured:

1- Print length (PL): Distance from heel to the third toe;

2- Toe spread (TS): Distance from the first to the fifth toe; and

3- Intermediate toe spread (ITS): Distance from the second to the fourth toe.

These three parameters were taken from the same legs of all subjects before nerve injury and also after nerve injury and three factors were calculated as follows:

1- Print length factor (PLF): Experimental PL-normal PL/ normal PL;

2- Toe spread factor (TSF): Experimental TS-normal TS/ normal TS; and 
3- Intermediate toe spread factor (ITSF): Experimental ITSnormal ITS/normal ITS.

SFI was calculated using these three factors by a formula reported by Bain et al. (3):

$\mathrm{SFl}=-38.3 \times \mathrm{PLF}+109.5 \times \mathrm{TSF}+13.3 \times \mathrm{ITSF}-8.8$

Sciatic Functional Index can be calculated between 0 and -100 with this formula, and 0 indicates normal function while -100 indicates a significant impairment. Therefore, SFI shows rate of retrogression in the function of the sciatic nerve after injury.

\section{Biochemical Measurements}

Tissue samples were kept in physiological saline (PS) at $-20^{\circ} \mathrm{C}$ and thawed at $4^{\circ} \mathrm{C}$ before biochemical measurements. They were weighted and put into glass tubes and then homogenized in two volumes $(\mathrm{w} / \mathrm{v})$ of $1.15 \%$ ice-cold $\mathrm{KCl}$ solution at 16000 rpm for 3 minutes in a homogenizer. Homogenates were centrifuged at $14000 \mathrm{rpm}$ for 45 minutes at $4^{\circ} \mathrm{C}$. CAT, SOD and GSH activities were determined by micro-enzyme-linked immunosorbent assay (micro-ELISA) method using ELISA kits for CAT, SOD and GSH (Eastbiopharm Co, Hangzhou) in the supernatant. CAT activities were given as $\mathrm{kU} / \mathrm{mg}$, SOD activities as U/mg and GSH activities as ng/mg.

\section{Statistical Evaluations}

Statistical evaluations were performed by a biostatistician using the Number Cruncher Statistical System 2007 software (Utah, USA). In addition to descriptive statistical methods (average and standard deviation), the Kruskal-Wallis test was used to compare groups and Dunn's test was to compare subgroups while the chi-square and Fisher's exact tests were used for comparison of qualitative data. Differences were considered significant when probability was lower than 0.05 .

\section{RESULTS}

None of the subjects died during the study. It was seen that the nerve became flat but its continuity was preserved after crush injury performed with an aneurysm clip and it was also seen that there was flask paralysis of leg and its nerve was crushed in all subjects. It must be noted that the paralysis was partially improved 48 hours after injury in all subjects of Group 4.

\section{Nerve Function}

The Sciatic Functional Index values of groups were significantly different $(p=0.0001)$ (Table I and Figure 1). The SFI values of Group 1 were significantly higher than values of Groups 2 and $3(p=0.004$ and $p=0.001$, respectively). The SFI values of Group 2 were significantly lower than values of Groups 3 and $4(p=0.002$ and $p=0.003$, respectively), and SFI values of Group 3 were significantly lower than values of Group $4(p=$ 0.018). However, the difference between SFI values of Group 1 and Group 4 was not significant $(p=0.089)$ (Table II).

\section{Biochemical Parameters}

The CAT, SOD and GSH activities of nerve tissues of the groups are shown in Table III and Figures 2, 3 and 4. All three parameters were significantly different between all groups (Table IV). ALA protection provided significantly higher antioxidant enzyme activities (for all of CAT, SOD and GSH) compared to the control group after 1 hour and also after 48 hours. Antioxidant activities that occurred 48 hours after injury were higher than the antioxidant activities that occurred 1 hour after injury in ALA groups.

Table I: Sciatic Functional Index Values of the Groups Before and After Operation

\begin{tabular}{lc}
\hline & SFI (average \pm SD) \\
\hline Group 1 & $-29.11 \pm 6.65$ \\
\hline Group 2 & $-75.14 \pm 10.85$ \\
\hline Group 3 & $-47.26 \pm 9.99$ \\
\hline Group 4 & $-35.1 \pm 6.98$ \\
\hline p & 0.0001 \\
\hline
\end{tabular}

SFI: Sciatic functional index, SD: Standard deviation.

Table II: Statistical Differences Between SFI Values of the Groups After Operation Provided by Dunn's Test

\begin{tabular}{ll}
\hline & $\mathbf{p}$ \\
\hline Group 1/Group 2 & $\mathbf{0 . 0 0 1}$ \\
\hline Group 1/Group 3 & $\mathbf{0 . 0 0 4}$ \\
\hline Group 1/Group 4 & 0.089 \\
\hline Group 2/Group 3 & $\mathbf{0 . 0 0 2}$ \\
\hline Group 2/Group 4 & $\mathbf{0 . 0 0 3}$ \\
\hline Group 3/Group 4 & $\mathbf{0 . 0 1 8}$
\end{tabular}

SFI: Sciatic functional index.

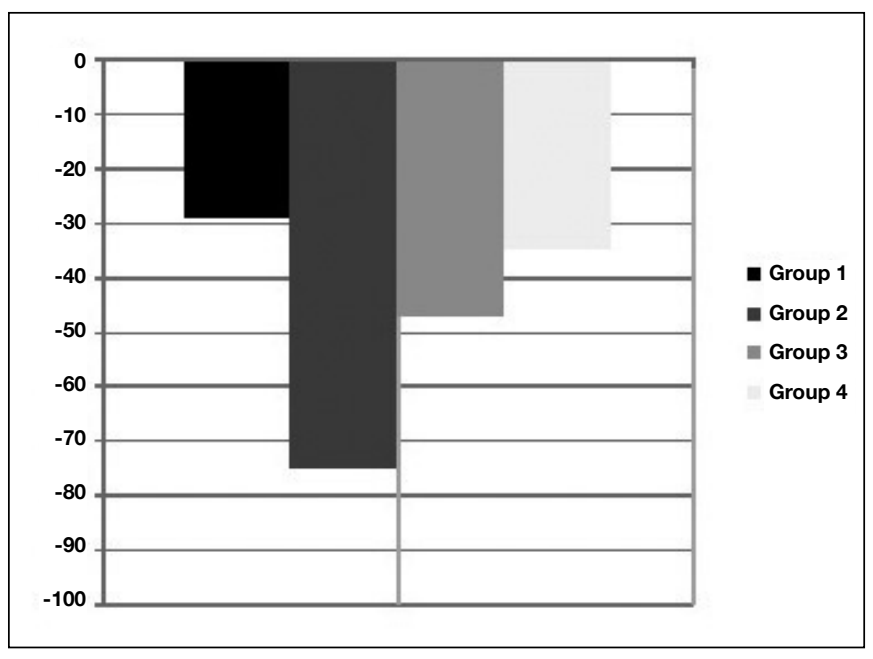

Figure 1: Graph showing SFI of the groups. 
Table III: CAT, SOD and GSH Activities of the Groups

\begin{tabular}{lccc}
\hline & CAT (kU/mg) (average \pm SD) & SOD (U/mg) (average \pm SD) & GSH (ng/mg) (average \pm SD) \\
\hline Group 1 & $\mathbf{1 0 5 . 6 8} \pm \mathbf{1 . 6 2}$ & $\mathbf{1 6 1 . 7 7 \pm 8 . 8 4}$ & $\mathbf{5 . 8 3} \pm \mathbf{0 . 2 1}$ \\
\hline Group 2 & $111.62 \pm 2.28$ & $214.39 \pm 8.05$ & $8.25 \pm 0.54$ \\
\hline Group 3 & $333.59 \pm 3.53$ & $300.37 \pm 2.72$ & $14.66 \pm 0.44$ \\
\hline Group 4 & $363.2 \pm 2.87$ & $323.79 \pm 5.7$ & $19.94 \pm 0.73$ \\
\hline p & 0.0001 & 0.0001 & 0.0001 \\
\hline
\end{tabular}

CAT: Catalase, SOD: Superoxide dismutase, GSH: Glutathione peroxidase.

Table IV: Statistical Differences Between Biochemical Parameters of the Groups Provided by Dunn's Test

\begin{tabular}{lccc}
\hline & p value for CAT & p value for SOD & p value for GSH \\
\hline Group 1/Group 2 & 0.002 & 0.002 & 0.002 \\
\hline Group 1/Group 3 & 0.001 & 0.001 & 0.001 \\
\hline Group 1/Group 4 & 0.001 & 0.001 & 0.001 \\
\hline Group 2/Group 3 & 0.001 & 0.002 & 0.002 \\
\hline Group 2/Group 4 & 0.001 & 0.001 & 0.001 \\
\hline Group 3/Group 4 & 0.002 & 0.002 & 0.002 \\
\hline
\end{tabular}

CAT: Catalase, SOD: Superoxide dismutase, GSH: Glutathione peroxidase.
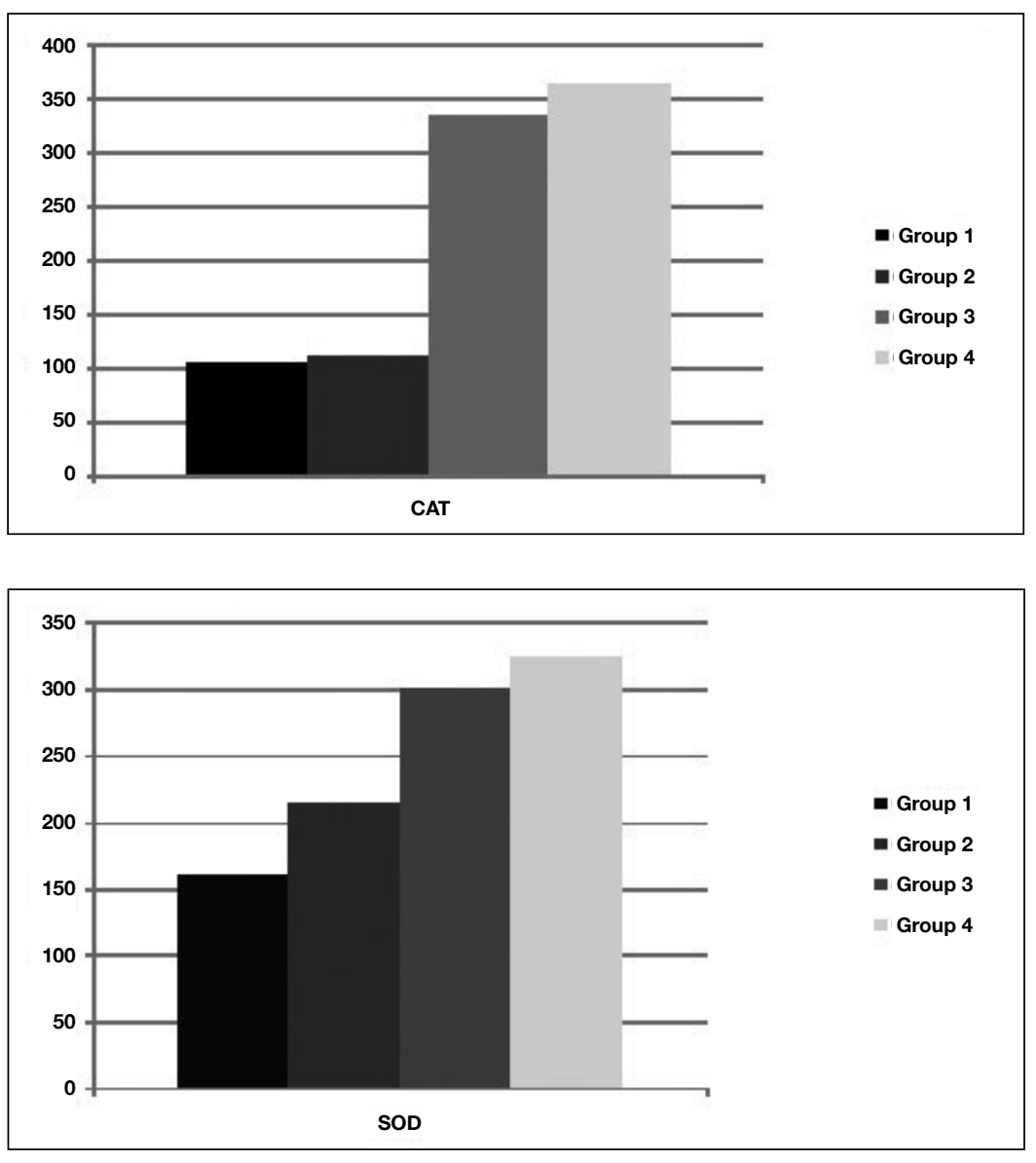

Figure 2: Graph showing CAT activity of the groups.

Figure 3: Graph showing SOD activity of the groups. 


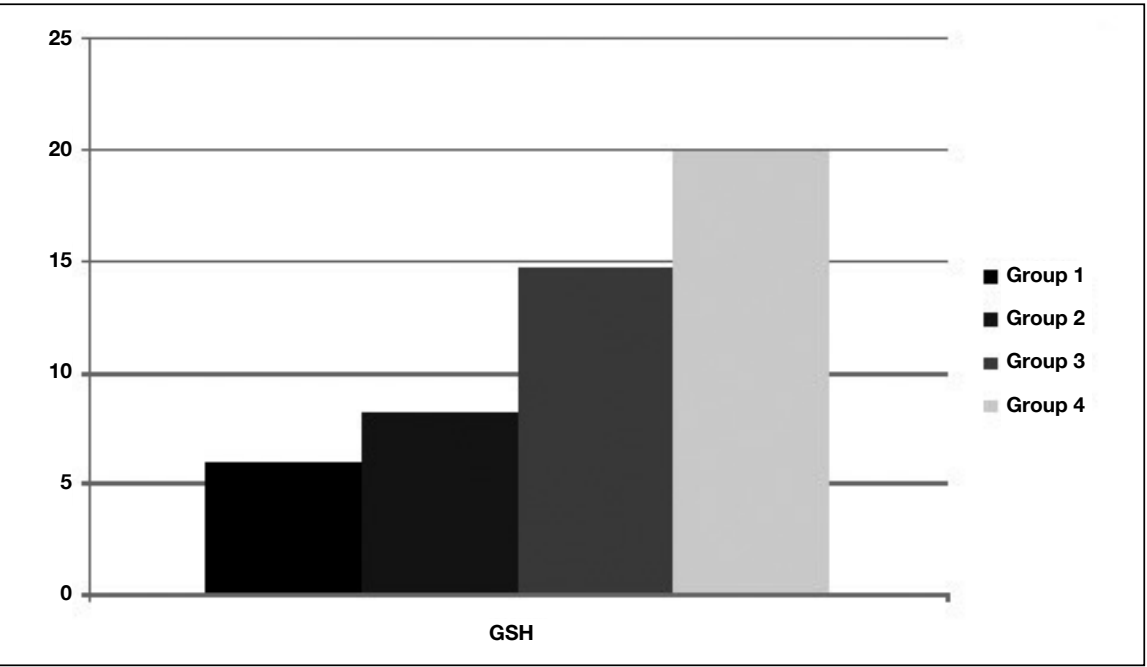

Figure 4: Graph showing GSH activity of the groups.

\section{DISCUSSION}

Peripheral nerve injury is a quite frequent cause of disability in the modern era and it may result in various degrees of neurological sequels from mild sensory deficits to whole motor, sensory and autonomic dysfunctions in the distributions of the affected nerves. Traffic accidents, falling from height and gunshot injuries in particular often cause crush type peripheral nerve injuries and their frequencies are increasing day by day.

In crush type peripheral nerve injury, axonotmesis and transient cessation of axoplasmic flux are the major nerve lesions (45), and good functional recovery can be expected much more commonly than in transection type injury because endoneurial sheath integrity is preserved. In clinical practice, surgical repair is usually required for the transection type but drug therapy is a more reliable choice to treat crush injuries (12).

There are a lot of studies evaluating the protective or therapeutic effects of various antioxidants related to the peripheral nerve injury model such as vitamin $\mathrm{E}$, ubiquinone, L-carnitine and agmatine $(1,22,33,38)$ or other substances such as cytidinediphosphocholine, rapamycin, tetanus toxin, platelet-rich plasma, insulin-like growth factor I, dexamethasone and acetyl salicylic acid $(5,8,9,12,17,23,29,39)$, or some energy types such as low level laser irradiation and low-frequency magnetic fields $(30,44)$.

ALA is a strong antioxidant and neuroprotective agent naturally occurring in the body, and is also present in some foods $(27,40)$. It is routinely used for the treatment of some pain disorders such as diabetic neuropathy (10). In addition, ALA was found to have a neuroprotective or therapeutic effects in some models mimicking various central nervous system disorders such as brain ischemia, endotoxic shock induced brain injury, subarachnoid hemorrhage, brain or spinal cord ischemiareperfusion injury, and spinal cord injury $(10,11,14,15,35,41)$. There were also some studies on the effect ALA on peripheral nervous system disorders. Melli et al. reported that ALA had a protective effect on mitochondrial damage and on neurotoxicity caused by chemotherapeutic agents (26). Tomassoni et al. reported that ALA has protective activity on nervous system lesions caused by chronic constriction injury of the peripheral nerve (40). Azizi et al. found that topical administration of ALA in a transection model of sciatic nerve provided faster healing (2). Mitsui et al. showed that ALA that was administered 3 days before ischemia resulted in a significant protective effect from moderate ischemia-reperfusion injury of the peripheral nerve (28). We chose to investigate the effects of ALA on peripheral crush type nerve injury because of good results with these studies. We planned a series of studies to evaluate first the protective and then the therapeutic effects of ALA, and this study investigating the protective effects is the first part.

The protective effect of ALA on peripheral nerve injury is probably due to some of its characteristics. The most important of them is its powerful antioxidant effect. It is capable of scavenging hydroxyl radicals and singlet oxygen. It also acts as a chelator of transition metals such as $\mathrm{Cu}, \mathrm{Mn}$ and $\mathrm{Zn}$. These actions contribute to reduced oxidative stress (28). Many experimental results show that both ALA and dihydrolipoic acid (DHLA), its reduced form, can improve the antioxidant capacity of tissue against different forms of oxidative stress $(37,40)$. Hydroxyl radicals, singlet oxygen, peroxynitrite, and hypochlorous acid are scavenged by ALA, and hydroxyl radicals, superoxide, peroxyl radical, peroxynitrite, nitric oxide, and hypochlorous acid are scavenged by DHLA (10). $A L A$ is known as an essential cofactor for mitochondrial bioenergetic enzymes (13). In addition, it was demonstrated that ALA contributes to other antioxidant systems such as coenzyme Q10, and vitamins C and E (15). It easily crosses the blood-brain barrier and it is accepted by human cells as a substrate. In addition, ALA is reduced to DHLA, and DHLA is not destroyed by free radicals, and it can be recycled from ALA. Moreover, these two molecules are amphipathic and they may act as antioxidants in both hydrophilic and lipophilic environments (41).

In crush type injury of a peripheral nerve, the pathological mechanism is not clear as in transection or avulsion type injuries because nerve continuity is maintained. Two pathological mechanisms may be responsible in these injuries: mechanical 
compression and ischemia $(4,9)$. In addition, it was demonstrated that both acute and chronic compression of nerves causes disruption of blood-brain barrier and edema within the nerve (22). In the lesion site of a peripheral nerve injury, the decrease in oxygenation and changes in morphology increase arachidonic acid metabolism and cause collection of unstable endoperoxides in intracellular and extracellular areas. In addition, in crush type injury, reperfusion after compression period redound formation of free radicals as in ischemia-reperfusion injuries (45). Both traumatic and ischemic injuries to central nervous system tissues were shown to result in increased glutamate release, sustained activation of glutamate receptors, and increased accumulation of calcium $\left(\mathrm{Ca}^{+2}\right)$. There is direct evidence that activation of glutamate receptors and the $\mathrm{Ca}^{+2}$ influx induces the formation of reactive oxygen species, superoxide anion, and hydrogen peroxide (10). Oxidative stress initiates lipid peroxidation cascades that lead to the damage of highly vulnerable cell membranes during the first few days after injury (10). Therefore, ALA and other antioxidants may reduce harmful effects of oxidative stress due to peripheral nerve injury.

Another possible mechanism of ALA's protective effect may be decrease of apoptosis. Apoptosis plays an important role in the death of the cell body of injured axons, schwann cells, phagocytic neutrophils and macrophages after peripheral nerve injury. The incidence of apoptosis-related cell death in dorsal root ganglion neurons following axonotmesis ranges from 20 to $50 \%$ (4). Death occurs more frequently when axonotmesis occurs proximally and in injuries involving sensory or cranial nerves. This process of injury-induced neuronal cell death remains poorly understood, but conditions within the microenvironment of the injury site are believed to be important. It was demonstrated that cell survival after injury is supported by the roles of schwann cells and presence of some trophic molecules such as nerve growth factor, brainderived neurotrophic factor, and others that appear to have an influence (4). Emmez et al. could not find a significant antiapoptotic effect of ALA in a spinal cord ischemia model in rats (10). On the other hand, it was shown that ALA causes a down-regulation of NF-KB that plays a fundamental role in the expression of various genes that are involved in the inflammatory response and also that are involved in cell apoptosis processes (16). In particular, acute treatments with ALA were shown to cause to both reduction of expression of NF-KB and of matrix metalloproteinase-9, an enzyme responsible for the degradation of the extracellular matrix (7). In addition, it was shown that ALA pre-treatment reduced radiation-induced apoptotic and necrotic cell death of granule cells and Purkinje cells in two experimental studies $(20,25)$.

Several endogenous antioxidant enzymes such as SOD, CAT and GSH can detoxify reactive oxygen species. SOD and CAT are concerned with the removal of superoxide anion and peroxide $(6,28)$. Their increase in tissue indicates an increase of antioxidant activity (37). GSH is a very important cellular antioxidant that protects cells from free radicals. It prevents oxidation of protein thiols to disulfides and therefore protects the activity of critical enzymes with active thiol groups (28). The decrease in the level of GSH increases susceptibility to oxidative damage $(10,42)$. It was suggested that ALA provides its antioxidant effect especially through GSH. In spinal cord ischemia models, Emmez et al. (10) and Tozlu et al. (41) demonstrated that ALA provided a significant increase in levels of tissue SOD and GSH activities. It increased de novo synthesis of cellular GSH by improving cysteine utilization (18). Some in vivo and in vitro experimental studies showed that administration of ALA increased the intracellular GSH level by $30-70 \%$ (19). In an experimental study, Melli et al. (26) reported that ALA increases the expression of frataxin. Fraxatin is a nuclear encoded, mitochondrial localized protein that is required for optimal functioning of mitochondria and its overexpression induces antioxidant cellular effects by activation of glutathione peroxidase (26).

Senoglu et al. demonstrated a significant neuroprotective effect of ALA on sciatic nerve tissue antioxidant activity in a crush type peripheral nerve injury model (37). They reported that ALA treatment caused a significant increase of tissue antioxidant enzyme activities in the early period after trauma. However, they did not support their results with functional or histological findings. We used a similar model but used an aneurysm clip instead of jeweler's clip to provide a more standard application of compression force to crush the sciatic nerve and we added measurement of GSH activity to CAT and SOD activities because ALA displays its antioxidant activity especially through GSH activity. In rat sciatic models, biochemical studies, nerve histomorphometry and electrophysiological studies are the most popular methods to assess oxidative stress and neural regeneration $(14,34,36)$. However, these data do not always correspond to functional recovery (39). Functional recovery is most important goal of the treatment of peripheral nerve injury. Therefore, we decided to evaluate the functional status of the subjects by SFI in addition to nerve tissue levels of antioxidants. A rat model was chosen because the rat sciatic nerve can be easily dissected and it is a well-studied model in literature $(2,5,9,12,17,29,31,37-39,44)$.

The SFI proposed by Bain et al. is one of the most commonly used parameters to assess the functional recovery of damaged rat sciatic nerves (3). It is an easy, cheap and quantitative method for the evaluation of sciatic nerve function in rats (12). However, Wang et al. advocated that the reliability of the SFI should be carefully assessed when using it as a single parameter to evaluate severe sciatic nerve injuries, such as transected sciatic nerve with gaps or long segment of crush injury (44). Monte-Raso et al. evaluated the reproducibility of the SFI in rats with severe crush injury using a 5000-g static load on a $5-\mathrm{mm}$ segment of the sciatic nerve (32). They concluded that the SFI parameter is only reliable beginning at three weeks after a severe lesion of the sciatic nerve. In our study, an aneurysm clip with a closing pressure of $135 \mathrm{~g}$ was used for 60 seconds to crush the sciatic nerve. It was thought that SFI is also a reliable method for evaluating sciatic nerve function in the early period after a crush injury that occurred with a lower pressure force level for partial improvement of paralysis in the subjects after 48 hours clinically. In addition, it is a reliable method for not only the improvement of SFI values but also for the improvement of the higher level of antioxidant enzyme activities in nerve tissue. 


\section{- CONCLUSION}

The findings of our study showed that pre-treatment with ALA before crush type peripheral nerve injury had significant protective effects on both nerve function and antioxidant activity of nerve tissue in the early period. Besides, although only 2 doses of ALA were administered, at 24 hours before injury and 1 hour before injury, and considering that the halflife of ALA is 25 minutes in humans, its protective effects were still marked 48 hours after injury both clinically and biochemically, although the effects were more prominent than 1 hour after injury. Furthermore, ALA administration provided similar functional results 48 hours after injury compared with the not injured (sham) group. With these promising results, we planned a second study to evaluate the therapeutic effects of ALA on crush type peripheral nerve injury by administration of the drug after nerve injury simulating peripheral nerve injury treatment in clinical practice.

Many studies have reported the effects of various antioxidant and anti-inflammatory agents in the treatment of peripheral nerve injury. Although these agents do not have a place in routine clinical use, they have shown positive effects on nerve healing in experimental studies (45). ALA, an essential co-factor for mitochondrial energy metabolism, is a natural product that can be synthesized de novo in mitochondria by lipoic acid synthase and also can be absorbed from the diet (10). It is both hydrophilic and lypophilic, and therefore it can easily be absorbed and can easily be distributed into all tissues of body. It is already used for the treatment of diabetic neuropathy without an important side effect. All of these characteristics make it a powerful antioxidant drug candidate for both prevention and treatment in various diseases including peripheral nerve injury.

\section{- REFERENCES}

1. Azizi A, Azizi S, Heshmatian B, Amini K: Improvement of functional recovery of transected peripheral nerve by means of chitosan grafts filled with vitamin E, pyrroloquinolinequinone and their combination. Int J Surg 12: 76-82, 2014

2. Azizi S, Heshmatian B, Amini K, Raisi A, Azimzadeh M: Alphalipoic acid loaded in chitosan conduit enhances sciatic nerve regeneration in rat. Iran J Basic Med Sci 18: 228-233, 2015

3. Bain JR, Mackinnon SE, Hunter DA: Functional evaluation of complete sciatic, peroneal, and posterior tibial nerve lesions in the rat. Plast Reconstr Surg 83:129-138, 1989

4. Burnett MG, Zager EL: Pathophysiology of peripheral nerve injury: A brief review. Neurosurg Focus 16 (5):1, 2004

5. Caner B, Kafa MI, Bekar A, Kurt MA, Karli N, Cansev M, Ulus $\mathrm{IH}$ : Intraperitoneal administration of CDP-choline or a combination of cytidine plus choline improves nerve regeneration and functional recovery in a rat model of sciatic nerve injury. Neurol Res 34:238-245, 2012

6. Cetinkaya A, Bulbuloglu E, Kantarceken B, Ciralik H, Belge Kurutas E, Buyukbese MA, Gumusalan Y: Effects of L-carnitine on oxidant/antioxidant status in acetic acid-induced colitis. Dig Dis Sci 51:488-494, 2006
7. Constantino M, Guaraldi C, Constantino D, De Grazia S, Unfer V: Peripheral neuropathy in obstetrics: Efficacy and safety of a-lipoic acid supplementation. Eur Rew Med Pharmacol Sci 18: 2766-2771, 2014

8. Ding T, Zhu C, Yin JB, Zhang T, Lu YC, Ren J, Li YQ: Slowreleasing rapamycin-coated bionic peripheral nerve scaffold promotes the regeneration of rat sciatic nerve after injury. Life Sci 122: 92-99, 2015

9. Emel E, Sonmez Ergun S, Kotan D, Basar Gursoy E, Parman $Y$, Zengin A, Nurten A: Effects of insulin-like growth factor-I and platelet-rich plasma on sciatic nerve crush injury in a rat model. J Neurosurg 114:522-528, 2011

10. Emmez H, Yildirim Z, Kale A, Tonge M, Durdag E, Borcek AO, Ucankus LN, Dogulu F, Kilic N, Baykaner MK: Anti-apoptotic and neuroprotective effects of alpha-lipoic acid on spinal cord ischemia-reperfusion injury in rabbits. Acta Neurochir 152: 1591-1601, 2010

11. Ersahin M, Toklu HZ, Cetinel S, Yuksel M, Erzik C, Berkman MZ, Yegen BC, Sener G: Alpha lipoic acid alleviates oxidative stress and preserves blood brain permeability in rats with subarachnoid hemorrhage. Neurochem Res 35:418-428, 2010

12. Feng $X$, Yuan $W$ : Dexamethasone enhanced functional recovery after sciatic nerve crush injury in rats. BioMed Res Int 2015:627923, 2015

13. Firuzi O, Miri R, Tavakkoli M, Saso L: Antioxidant therapy: Current status and future prospects. Curr Med Chem 18: 3871-3888, 2011

14. Gonzalez-Perez O, Gonzalez-Castaneda RE, Huerta M, Luquin S, Gomez-Pinedo U, Sanchez-Almaraz E, NavarroRuiz A, Garcia-Estrada J: Beneficial effects of a-lipoic acid plus vitamin $\mathrm{E}$ on neurological deficit, reactive gliosis and neuronal remodeling in the penumbra of the ischemic rat brain. Neurosci Let 321:100-104, 2002

15. Goraca A, Aslanowicz-Antkowiak K: Prophylaxis with a-lipoic acid against lipopolysaccharide-induced brain injury in rats. Arch Immunol Ther Exp 57:141-146, 2009

16. Goraca A, Huk-Kolega H, Piechota A, Kleniewska P, Ciejka E, Skibska B: Lipoic acid-biological activity and therapeutic potential. Pharmacol Rep 63:849-858, 2011

17. Gunay H, Kucuk L, Erbas O, Calis Atamaz F, Kucuk U, Coskunol E: The effectiveness of tetanus toxin on sciatic nerve regeneration: A preliminary experimental study in rats. Microsurgery 34(5):384-389, 2014

18. Han D, Handelman G, Marcocci L, Sen CK, Roy S, Kobuchi $\mathrm{H}$, Tritschler HJ, Flohé L, Packer L: Lipoic acid increases de novo synthesis of cellular glutathione by improving cysteine utilization. Biofactors 6(3):321-338, 1997

19. Han D, Tritschler HJ, Packer L: Alpha-lipoic acid increases intracellular glutathione in a human T-lymphocyte Jurkat cell line. Biochem Biophys Res Commun 207:258-264, 1995

20. Jia Z, Zhu H, Vitto MJ, Misra BR, Li Y, Misra HP: Alpha lipoic acid potently inhibits peroxynitrite-mediated DNA strand breakage and hydroxyl radical formation: Implications for the neuroprotective effects of alpha-lipoic acid. Mol Cell Biochem 323:131-138, 2009 
21. Kanaya F, Firrell JC, Breidenbach WC: Sciatic function index, nerve conduction tests, muscle contraction, and axon morphometry as indicators of regeneration. Plast Reconstr Surg 98: 1264-1271; discussion 1272-1274, 1996

22. Kotil K, Kırali M, Eras M, Bilge T, Uzun H: Neuroprotective effects of acetyl-L-carnithine in experimental chronic compression neuropathy. A prospective, randomized and plasebo-control trials. Turk Neurosurg 17: 67-77, 2007

23. Kucuk L, Gunay H, Erbas O, Kucuk U, Atamaz F, Coskunol E: Effects of platelet-rich plasma on nerve regeneration in a rat model. Acta Orthop Traumatol Turc 48: 449-454, 2014

24. Lee WY, Orestes P, Latham J, Naik AK, Nelson MT, Vitko I, Perez-Reyes E, Jevtovic-Todorovic V, Todorovic SM: Molecular mechanisms of lipoic acid modulation of T-type calcium channels in pain pathway. J Neurosci. 29: 9500-9509, 2009

25. Manda K, Ueno M, Moritake T, Anzai K: Radiation-induced cognitive dysfunction and cerebellar oxidative stress in mice: Protective effect of alpha-lipoic acid. Behav Brain Res 177: 7-14, 2007

26. Melli G, Taiana M, Camozzi F, Triolo D, Podini P, Quattrini A, Taroni F, Lauria G: Alpha-lipoic acid prevents mitochondrial damage and neurotoxicity in experimental chemotherapy neuropathy. Exp Neurol 214: 276-284, 2008

27. Memeo A, Loiero M: Thioctic acid and acetyl-L-carnitine in the treatment of sciatic pain caused by a herniated disc. A randomized, double-blind, comparative study. Clin Drug Invest 28: 495-500, 2008

28. Mitsui Y, Schmelzer JD, Zollman PJ, Mitsui M, Tritschler HJ, Low PA: Alpha-lipoic acid provides neuroprotection from ischemia-reperfusion injury of peripheral nerve. J Neurol Sci 163: 11-16, 1999

29. Mohammadi R, Amini K, Abdollahi-Pirbazari M, Yousefi A: Acetyl salicylic acid locally enhances functional recovery after sciatic nerve transection in rat. Neurol Med Chir (Tokyo) 53: 839-846, 2013

30. Mohammadi R, Faraji D, Alemi H, Mokarizadeh A: Pulsed electromagnetic fields accelerate functional recovery of transected sciatic nerve bridged by chitosan conduit: An animal model study. Int J Surg 12: 1278-1285, 2014

31. Mohammadi R, Yadegarazadi MJ, Amini K: Peripheral nerve regeneration following transection injury to rat sciatic nerve by local application of adrenocorticotropic hormone. J Craniomaxillofac Surg 42: 784-789, 2014

32. Monte-Raso VV, Barbieri $\mathrm{CH}$, Mazzer N, Yamasita AC, Barbieri G: Is the sciatic functional index always reliable and reproducible? J Neurosci Methods 170: 255-261, 2008
33. Moradi Z, Azizi S, Hobbenaghi R: Ubiquinone improves functional recovery and morphometric indices of sciatic nerve regeneration. Iran J Veterinary Res 15:392-396, 2014

34. Near SL, Whalen LR, Miller JA, İshii DN: Insulin-like growth factor II stimulates motor nerve regeneration. Proc Natl Acad Sci 89: 11716-11720, 1992

35. Panigrahi M, Sadguna Y, Shivakumar BR, Kolluri SV, Roy S, Packer L, Ravindranath V: Alpha--lipoic acid protects against reperfusion injury following cerebral ischemia in rats. Brain Res 717: 184-188, 1996

36. Raducan A, Mirica S, Duicu O, Raducan S, Muntean D, FiraMiladinescu O, Lighezan R: Morphological and functional aspects of sciatic nerve regeneration after crush injury. Rom $\mathrm{J}$ Morphol Embryol 54 Suppl 3:735-739, 2013

37. Senoglu M, Nacitarhan V, Kurutas EB, Senoglu N, Altun I, Atli Y, Ozbag D: Intraperitoneal alpha-lipoic acid to prevent neural damage after crush injury to the rat sciatic nerve. J Brachial Plex Peripher Nerve Inj 4(1): 22, 2009

38. Sezer A, Guclu B, Kazanci B, Cakir M, Coban MK: Neuroprotective effects of agmatine in experimental peripheral nerve injury in rats: A prospective randomized and placebocontrolled trial. Turk Neurosurg 24:196-201, 2014

39. Suslu H, Altun M, Erdivanli B, Turan Suslu H: Comparison of the effects of local and systemic dexamethasone on the rat traumatic sciatic nerve model. Turk Neurosurg 23:623-629, 2013

40. Tomassoni D, Amenta F, Di Cesare Mannelli L, Ghelardini C, Nwankwo IE, Pacini A, Tayebati SK: Neuroprotective activity of thioctic acid in central nervous system lesions consequent to peripheral nerve injury. BioMed Res Int 9: 985093, 2013

41. Tozlu HZ, Hakan T, Celik H, Biber N, Erzik C, Ogunc AV, Akakin D, Cikler E, Cetinel S, Ersahin M, Sener G: Neuroprotective effects of alpha-lipoic acid in experimental spinal cord injury in rats. J Spinal Cord Med 33:401-409, 2010

42. Vallianou N, Evangelopoulos A, Koutalas P: Alpha-lipoic acid and diabetic neuropathy. Rew Diabetic Studies 6:230-236, 2009

43. Varejão AS, Meek MF, Ferreira AJ, Patrício JA, Cabrita AM: Functional evaluation of peripheral nerve regeneration in the rat: Walking track analysis. J Neurosci Methods. 108:1-9, 2001

44. Wang CZ, Chen YJ, Wang YH, Yeh ML, Huang MH, Ho ML, Liang $\mathrm{Jl}$, Chen $\mathrm{CH}$ : Low-level laser irradiation improves functional recovery and nerve regeneration in sciatic nerve crush rat injury model. Plos One 2014; 9: 8, e103348, 2014

45. Yuce S, Gokce EC, Isikdemir A, Koc ER, Cemil DB, Gokce A, Sargon MF: An experimental comparison of the effects of propolis, curcumin, and methylprednisolone on crush injuries of the sciatic nerve. Ann Plast Surg 74: 684-692, 2015 